\title{
Large decline in the abundance of a targeted tropical lethrinid in areas open and closed to fishing
}

\author{
Dianne L. McLean ${ }^{1, *}$, Euan S. Harvey ${ }^{2}$, David V. Fairclough ${ }^{3}$, Stephen J. Newman ${ }^{3}$ \\ ${ }^{1}$ Centre for Marine Futures and ${ }^{2}$ School of Plant Biology, The University of Western Australia, 35 Stirling Hwy, Crawley, \\ Western Australia 6009, Australia \\ ${ }^{3}$ Western Australian Fisheries and Marine Research Laboratories, Department of Fisheries, Government of Western \\ Australia, PO Box 20, North Beach, Western Australia 6920, Australia
}

\begin{abstract}
In Western Australia, one of the most important commercially and recreationally targeted, yet understudied fish species is the redthroat emperor Lethrinus miniatus. The present study aimed to compare the relative abundance and size of L. miniatus in areas open and closed to fishing at the Houtman Abrolhos Islands and to assess change in these populations over a $5 \mathrm{yr}$ period. Baited remote underwater stereo-video systems (stereo BRUVs) were used to conduct the surveys from 2005 to 2009, which included different depths and locations across 4 geographically separated groups of islands. Data showed high spatial variability in the relative abundance of $L$. miniatus across depths, sites, and island group locations. In 2005 and 2006, L. miniatus were more abundant at depths of 22 to $26 \mathrm{~m}$ than in 8 to $12 \mathrm{~m}$. At this time, individuals were also $1.3 \times$ more abundant and $10 \%$ larger in length in areas closed to fishing than in areas open to fishing. Starting in 2007, however, relative abundances of $L$. miniatus declined so markedly that in 2009 only $20 \%$ of the 2005 and 2006 numbers remained. This decline removed the disparity between depths, closed areas and fished locations. Unlike with relative abundance, $L$. miniatus remained consistently larger inside closed areas (mean $370 \mathrm{~mm}$ fork length) than in areas open to fishing (mean $350 \mathrm{~mm}$ ). Of the 483 individuals measured across the 5 yr of the study, $98 \%$ were larger than the minimum legal size for retention, and therefore subject to harvest. Mean lengths increased each year, as the size structure of the population reflected an aging cohort. With declines in measured relative abundance in excess of $80 \%$ over the past $5 \mathrm{yr}$, the sustainability of $L$. miniatus assemblages at the Houtman Abrolhos Islands is in question.
\end{abstract}

KEY WORDS: Lethrinus miniatus $\cdot$ Fish length $\cdot$ Fishing $\cdot$ Stereo video $\cdot$ Houtman $\cdot$ Abrolhos Islands Resale or republication not permitted without written consent of the publisher

\section{INTRODUCTION}

Throughout the tropics and sub-tropics, species of the Lethrinidae family are some of the most heavily targeted and highly prized fishes (Carpenter \& Allen 1989, Mapstone et al. 2004, Welch et al. 2008). Some lethrinids have life history characteristics that make them particularly vulnerable to overfishing, e.g. they are long lived and slow growing (e.g. Lethrinus nebulosus), and some are protogynous hermaphrodites (e.g. L. miniatus, L. atkinsoni) (Bean et al. 2003, Ebisawa \& Ozawa 2009, Marriott et al. 2010). A strategy commonly employed for protecting and rebuilding stocks of vulnerable and exploited species with these life history characteristics is to set aside areas of the ocean in marine protected areas (MPAs) (Halpern 2003, Harborne et al. 2008). MPAs that have been established for long periods of time are more likely to benefit longlived, slow-growing lethrinid species, at least at a local scale (Molloy et al. 2008). Indeed, greater abundance and size of lethrinid species inside MPAs compared to areas open to fishing have been documented (Begg et al. 2005, Watson et al. 2007, 2009).

In Australia, one of the largest and most common lethrinids with high commercial importance is the redthroat emperor Lethrinus miniatus (Mapstone et al. 
2004, Fairclough et al. 2009). In Western Australia, L. miniatus is one of the most important commercially fished species (line fishing), comprising $14 \%$ of the total commercial catch and $80 \%$ of the commercial emperor catch in the west coast bioregion (Fairclough et al. 2008). A large part of this catch is taken in a relatively small area surrounding the Houtman Abrolhos Islands and in waters immediately to the north, corresponding to areas in which L. miniatus are at the southern limit of their range. At the southern limit of their range, fish species can exhibit highly variable spawning activity (sometimes spawning omission; Fennessy \& Sadovy 2002, Williams et al. 2006) and as a result have a reduced resilience to perturbations including overfishing. For L. miniatus in Western Australia, this potential low resilience is further exacerbated by a low genetic diversity suggestive of a genetically impoverished population (van Herwerden et al. 2009).

To date, and despite the species' commercial and recreational importance, no research has examined the impact of fishing or fisheries management strategies on Lethrinus miniatus in Western Australia. Current fisheries regulations that exist in Western Australia to manage the demersal suite of fish species that includes L. miniatus comprise the following: minimum legal lengths, recreational bag limits, a 2 mo seasonal closure to recreational fishing (October 15-December 15), and restrictions on effort and total allowable catch in the commercial sector. The protogynous sexual strategy of L. miniatus, however, complicates the effectiveness of these regulations, as overfishing of males could potentially lead to changes in the sex ratio, sperm limitation, and an undesirable reduction in the size and/or age at sex change of populations (e.g. Platten et al. 2002, Molloy et al. 2008). Alternative management strategies, such as a maximum legal length limit, have been suggested (Williams et al. 2006), but the effectiveness of these types of regulation would rely on high release survival of those large individuals, which comprise males and the most fecund females. Targeted fishery closures (areas closed to fishing) are another fisheries management tool used in Western Australia to protect fish biodiversity and vulnerable and targeted fish species (Penn \& Fletcher 2010, Woodley et al. 2010). Only a small number of no-take areas exist, however, covering less than approximately $0.3 \%$ of Western Australia's state waters (Western Australia Department of Environment and Conservation and Department of Fisheries statistics).

Some of the oldest closed areas in Western Australia exist at the Houtman Abrolhos Islands. They were established in 1994 and do not allow fishing for scalefish species (Department of Fisheries, Western Australia 1998). The 4 closed areas at the Abrolhos (also referred to as reef observation areas; ROAs) were established with the goal of protecting valuable and vulnerable reef fish and their habitats (Nardi et al. 2004) and thus have similar goals to the globally recognised MPAs, as defined by the IUCN (Kelleher 1999). These closed areas are not strictly no-take, as commercial fishing for rock lobster is permitted within their boundaries. A number of studies conducted in recent years have reported higher relative abundances and sizes of Lethrinus miniatus inside these closed areas than in areas open to fishing at the Houtman Abrolhos Islands (Watson et al. 2007, 2009). Since these studies were completed, however, there have been changes to fisheries regulations, evidence of illegal fishing, and indications that the abundances of some heavily targeted species are declining, including L. miniatus ( $\mathrm{T}$. Green pers. comm., Department of Fisheries Western Australia, authors' unpubl. data).

The present study assesses change in the relative abundance and size of Lethrinus miniatus between areas open and closed to fishing across a $5 \mathrm{yr}$ period at the Houtman Abrolhos Islands. Incorporated into the study was the additional influence of depth and island group location given the spatial extent of the islands (>100 km) and indications that L. miniatus may exhibit depth preferences (Williams et al. 2003). Results of the study will be discussed in relation to current fisheries regulations and levels of fishing activity with consideration of the life history characteristics of $L$. miniatus populations at the Houtman Abrolhos Islands.

\section{MATERIALS AND METHODS}

Study site. The Houtman Abrolhos Islands are located $60 \mathrm{~km}$ offshore from the mid-west coast of Western Australia between $28^{\circ} 15^{\prime} \mathrm{S}$ and $29^{\circ} 00^{\prime} \mathrm{S}$ and are located in the mid-west zone of the fishery (Fig. 1). They are comprised of 4 groups of islands surrounded by the most southern true coral reefs of the Indian Ocean. The island groups (North Island, Wallabi group, Easter group, and Pelsaert group) run in a north-south direction parallel to the mainland, spanning approximately $100 \mathrm{~km}$. Each island group possesses an area closed to scalefish fishing (ROA), with the Wallabi group ROA being the largest of the 4 $\left(27.44 \mathrm{~km}^{2}\right)$, followed by the Easter group ROA $\left(22.29 \mathrm{~km}^{2}\right)$, the Pelsaert group ROA $\left(13.72 \mathrm{~km}^{2}\right)$, and the North Island ROA $\left(2.78 \mathrm{~km}^{2}\right)$. The ROAs were established in 1994 and were therefore 10 to $15 \mathrm{yr}$ old at the time of the study.

Surveys, using baited remote underwater video systems (stereo BRUVs), were carried out in May of each year from 2005 to 2009 (5 yr), with each survey lasting 4 to 5 d. In 2005 and 2006 the Wallabi, Easter, and Pel- 


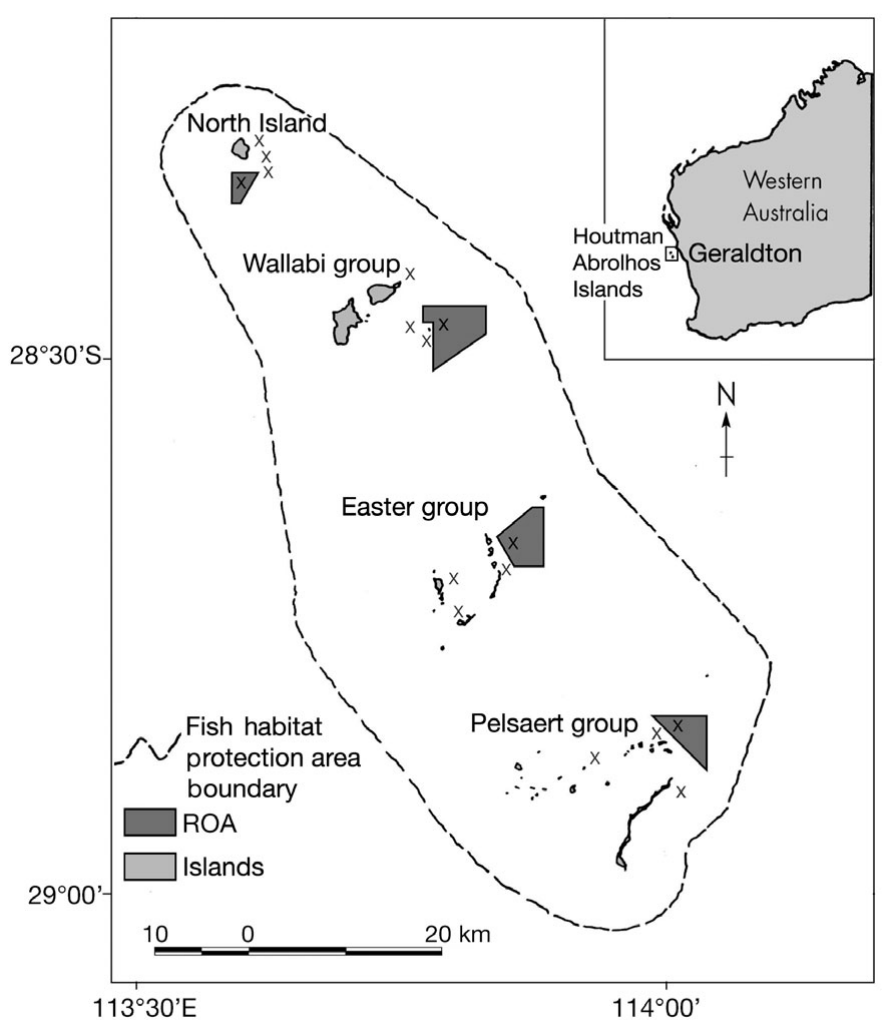

Fig. 1. Houtman Abrolhos Islands, Western Australia. Location of each island group and area closed to fishing ( $X$ in the reef observation area, ROA) is shown in addition to the 3 areas open to fishing $(X)$ surveyed within each island group

saert groups were surveyed, while North Island was added to the survey design in 2007 and continued in subsequent surveys. At each island group, stereo BRUV surveys were conducted within the closed area and at 3 locations open to fishing (Fig. 1). Shallow (8 to $12 \mathrm{~m}$ ) and deep (22 to $26 \mathrm{~m}$ ) reef slopes were surveyed at each open and closed location. Multiple fished locations (3) were surveyed for each closed area because areas open to fishing typically have more highly variable assemblages of fish and therefore the addition of multiple fished locations adds more power to statistical tests. Depths $>26 \mathrm{~m}$ were not surveyed due to habitat differences (coral rubble and sand) and the relatively small area available within ROA locations at these depths. There was insufficient area available for deep sites (22 to $26 \mathrm{~m}$ ) within the North Island ROA; therefore only shallow sites were surveyed at that location. Using direct observation, echo-sounder readings and the skipper's knowledge, care was taken to standardise surveys by habitat (predominantly coral). While each year the same open and closed locations were surveyed, deployments were haphazardly made within these locations. Five replicate deployments were made for each combination of Island group $\times$
Location (1 closed and 3 open to fishing within each Island group) $\times$ Depth. For 2005 and 2006, this gave a total of 120 surveys, and for 2007 to 2009 a total of 140 each yr.

Sampling technique. Detailed information on the design and calibration of remote stereo-video systems and the use and analysis of video footage obtained from them can be found in the literature (Harvey \& Shortis 1996, 1998, Harvey et al. 2001, 2002). Two SONY handy-cams (models used included HC 15E and CX7) are mounted $0.7 \mathrm{~m}$ apart on a base bar and inwardly converged to provide an overlapping field of view with visibility of at least $10 \mathrm{~m}$ distance. Importantly, the use of stereo-video allows accurate estimates of distance (Harvey et al. 2004). The standardized field of view sampled by the stereo BRUV system in this study was from 0.3 to $8 \mathrm{~m}$, inclusive, from the cameras.

After deployment by small boat, the stereo BRUVs were left to film for $60 \mathrm{~min}$ on the seafloor. The boat departed the area immediately after deployment. Ten stereo BRUV systems were deployed consecutively to maximise sampling efficiency. Bait consisted of $800 \mathrm{~g}$ of pilchards Sardinops sp. in a plastic-coated wire mesh basket that was suspended $1.2 \mathrm{~m}$ in front of the 2 cameras. The pilchards were crushed to promote dispersal of the fish oil and flesh. Adjacent sites were separated by 250 to $400 \mathrm{~m}$ to reduce the likelihood of fish moving between sites within the sampling period (see Cappo et al. 2001). Upon retrieval, footage was immediately examined to ensure that the stereo BRUV system landed upright to film horizontally along the substrate and that the field of view was not obstructed by habitat. Where necessary, systems were redeployed immediately at a different location 250 to $400 \mathrm{~m}$ away or at the same site on a subsequent day. Visibility was consistently good throughout the study (>8 m). All surveys were conducted between 08:00 and 16:30 h to minimise diurnal influences on the fish assemblages.

Concerns about potential biases associated with using the stereo BRUV technique revolve largely around the use of bait; in particular, how the use of bait may modify the behaviour of individuals and how bait plume dynamics might vary with depth and localised conditions. For discussion on these issues see Watson et al. $(2005,2009)$; suffice it to say that we surveyed sites of similar habitat, depth and exposure in locations open and closed to fishing to minimise these effects. Thus, while stereo BRUVs can provide relative, as opposed to absolute, measures of either densities or sizes of fish, we assumed that any methodological biases or localised effects were not correlated in any systematic or directional way with the areas being contrasted (e.g. inside versus outside closed areas). Stereo BRUVs can survey a broad range of sizes of 
Lethrinidae species with individuals as small as $40 \mathrm{~mm}$ and as large as $900 \mathrm{~mm}$ recorded on footage in Western Australia (authors' unpubl. data). We would therefore expect that, if present, juvenile Lethrinus miniatus would be surveyed by stereo BRUVs.

Image analysis. Relative abundance counts for Lethrinus miniatus from each stereo BRUV deployment were obtained by examining footage from the right camera only. Relative abundance is defined as the maximum number of L. miniatus (MaxN) present in the field of view of the right camera at the same time (Priede et al. 1994, Cappo et al. 2004). This measure avoids repeated counts of the same individual and gives a conservative measure of relative abundance, as often only a portion of the total number of individuals in the area may be viewed at one time (Willis et al. 2000). In the first 2 yr of the study, the Australian Institute of Marine Science BRUVS Access Database was used to obtain measures of MaxN (BRUVS1.5.mdb). More recently, the purpose-built program EventMeasure (SeaGIS 2008) was used for measures of MaxN. The change in programs used has no influence on the MaxN values obtained. Information on feeding behaviour was gleaned from recording the time at which the first individual fed directly from the bait basket for every deployment.

For measurement of lengths of Lethrinus miniatus, video footage was captured onto computers in audio video interleave (AVI) format. Measurements of fork length (snout to fork; FL) were then obtained using PhotoMeasure (SeaGIS 2008), a stereo-photo comparator software that was specifically written for obtaining length measurements from stereo images. As the FL of fish was measured, lengths reported are less than total length (TL), which is used in regulating minimum legal length for retention for this species. A TL of $280 \mathrm{~mm}$ (minimum legal size) is approximately $255 \mathrm{~mm}$ FL; where $\mathrm{TL}=9.6+1.0575 \mathrm{FL} \pm 4.7$ (Leigh et al. 2006). To avoid making repeated measurements of the lengths of the same individuals, measures of length were made at the time of MaxN. This MaxN 'time' refers to the corresponding amount of time that all individuals remained within the field of view of the cameras to enable measurement. Measurements of $L$. miniatus length were limited to those recorded within a maximum distance of $8 \mathrm{~m}$ from the cameras; these both ensured accurate and precise measurements as well as a standardized sampling unit. The software calculates both distance from the cameras and length at the same time; therefore, in order to maintain a standardised sampling unit, measurements of individuals further than $8 \mathrm{~m}$ from the cameras were discarded.

A single behavioural measurement was recorded; the time at which Lethrinus miniatus first fed directly from the bait bag (minutes into the 60 min recording).
This behavioural measurement could be compared to the same measure collected for other targeted species (D. McLean unpubl. data) and is discussed in relation to the likelihood of capture of L. miniatus.

Data analysis. The sampling design consisted of 5 factors: Year (Y, 5 levels, random: 2005 to 2009), Island group (G, 4 levels, fixed: Pelsaert, Easter, Wallabi, North), Status (St, 2 levels, fixed: closed vs. open), Site $(\mathrm{S}$, random, nested in Island group $\times$ Status, with one level in closed and 3 levels in areas open to fishing) and Depth (D, 2 levels, fixed: 8 to $12 \mathrm{~m}, 22$ to $26 \mathrm{~m}$ ). Note that for MaxN data each stereo BRUV deployment was considered a variable, while for length measurements each individual fish was considered a variable and assigned the appropriate 5 factors listed in the experimental design. Although a univariate data set, the data for MaxN and length were analysed using permutational multivariate analysis of variance (PERMANOVA; Anderson 2001) as, unlike ANOVA/ MANOVA techniques, PERMANOVA does not assume normality of errors. Furthermore, PERMANOVA partitions variation for complex experimental designs such as this. All univariate analyses were conducted using the Euclidean distance dissimilarity measure on raw length data and on fourth-root-transformed relative abundance data, as the data contained many zero counts. For length data, several 4-way interaction terms were identified to have one or more empty cells and were therefore removed from the model. After removal the model was re-run. Pairwise tests were performed for significant interaction terms using PERMANOVA. Significant interaction terms in the model were examined first by conducting appropriate pairwise comparisons. Where mean squares and estimated components of variation for these interactions were small, higher level interaction or main effect terms were then sequentially examined.

Kolmogorov-Smirnov (K-S) goodness of fit tests were conducted to determine whether size-frequency distributions differed across the years of the study. A Bonferroni correction was performed to correct for multiple comparisons between size-frequency distributions by dividing $\alpha$ by the number of comparisons made. Differences in length for factors of the study are also illustrated graphically or by differences in means.

\section{RESULTS}

\section{Relative abundance}

A total of 564 Lethrinus miniatus were recorded (at the time of MaxN) from the 5 yr study, with the highest numbers observed in 2005 (Table 1). Not only was this species most abundant in the first $2 \mathrm{yr}$ of the study, it 


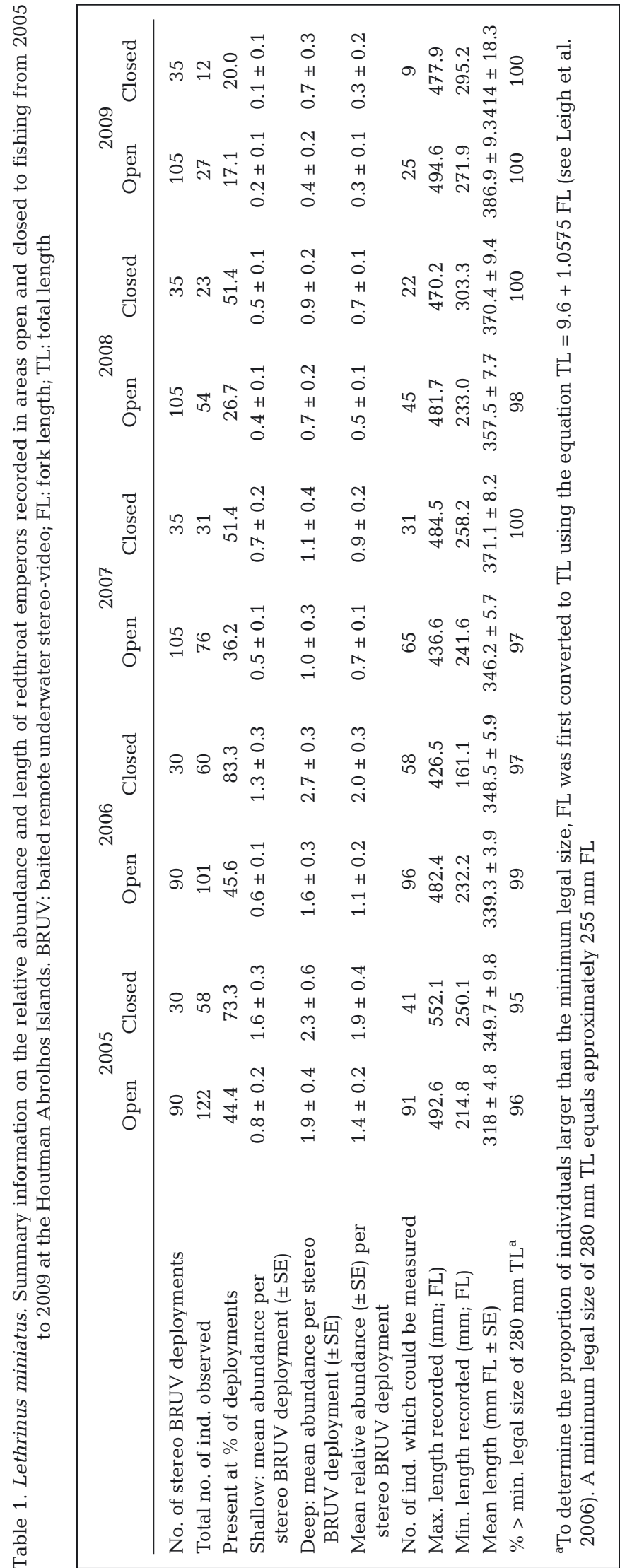

was also much more commonly observed on deployments in 2005 (44 to $73 \%$ ) and 2006 (46 to $83 \%$ ) than in later years (17 to $51 \%$; Table 1$)$. Schools of up to 12 individuals were observed in 2005 and 2006, but only comprised up to a maximum of 6 individuals in subsequent years.

A significant 4-way interaction term in the PERMANOVA model highlights the high variability in numbers of Lethrinus miniatus across years and at different spatial scales within the Houtman Abrolhos system (Table 2). The relative abundance of $L$. miniatus varied across years with status and depth (3-way $\mathrm{Y} \times \mathrm{St}$ $\times$ D interaction; Table 2; Fig. 2). Regardless of depth, the relative abundance of $L$. miniatus declined from 2005 and 2006 through to 2009 both inside and outside closed areas (Fig. 2; pairwise tests $\mathrm{p}<0.05$ ). However, this decrease was more pronounced in deep than in shallow habitats (Fig. 2). An effect of protection was evident in shallow habitats only in 2005 where $L$. miniatus were more abundant inside closed areas than in areas open to fishing (pairwise test St $\times \mathrm{D}, t=3.21$, $p=0.01$; Fig. 2a). This was the only recorded effect of protection on the relative abundance of $L$. miniatus during the 5 yr study.

A significant 3-way interaction of $\mathrm{Y} \times \mathrm{G} \times \mathrm{D}$ was also evident (Table 2 ) and was largely caused by a substantial decline in the relative abundance of Lethrinus miniatus from 2005-2006 to 2007-2009 in deep habitats of the Easter group (pairwise tests $\mathrm{Y} \times \mathrm{G} \times \mathrm{D}$ all $\mathrm{p}<$
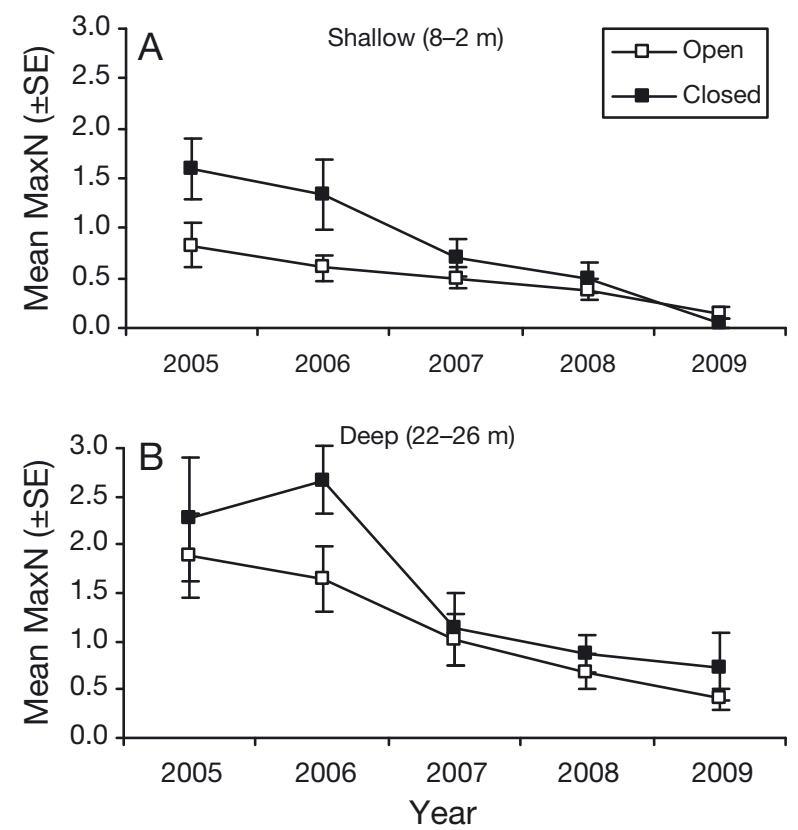

Fig. 2. Lethrinus miniatus. Mean $( \pm \mathrm{SE})$ relative abundance $(\mathrm{MaxN})$ in areas open and closed to fishing in (A) shallow and (B) deep habitats at the Houtman Abrolhos Islands between 2005 and 2009 
Table 2. Lethrinus miniatus. Results of permutational multivariate analysis of variance (PERMANOVA) based on Euclidean distance dissimilarity of fourthroot transformed relative abundance $(\mathrm{MaxN})$ data for redthroat emperors in response to the factors Year (Y), Island group (G), Status (St), Site (Si), Depth (D) and their interactions. Perm: permutation. Bold: significant at 0.05 level

\begin{tabular}{|c|c|c|c|c|c|}
\hline Source & $\mathrm{df}$ & MS & Pseudo- $F$ & $\mathrm{p}($ perm) & Perms \\
\hline Year (Y) & 4 & 4.4 & 14.8 & $<0.01$ & 9965 \\
\hline Island group $(\mathrm{G})$ & 3 & 6.6 & 1.4 & 0.2 & 9931 \\
\hline Status (St) & 1 & 3.4 & 1.0 & 0.4 & 9951 \\
\hline Depth (D) & 1 & 4.1 & 1.8 & 0.2 & 9948 \\
\hline $\mathrm{Y} \times \mathrm{G}^{\mathrm{a}}$ & 10 & 0.2 & 0.6 & 0.8 & 9937 \\
\hline $\mathrm{Y} \times \mathrm{St}$ & 4 & 0.4 & 1.4 & 0.3 & 9954 \\
\hline $\mathrm{Y} \times \mathrm{D}$ & 4 & 0.3 & 3.3 & 0.03 & 9948 \\
\hline $\mathrm{G} \times \mathrm{St}$ & 3 & 0.9 & 0.2 & 1.0 & 9934 \\
\hline $\mathrm{G} \times \mathrm{D}^{\mathrm{a}}$ & 2 & 1.1 & 0.5 & 0.9 & 9946 \\
\hline St $\times D$ & 1 & 0.0 & 0.0 & 1.0 & 9951 \\
\hline $\mathrm{Si}(\mathrm{G} \times \mathrm{St})$ & 8 & 5.0 & 16.8 & $<0.01$ & 9939 \\
\hline $\mathrm{Y} \times \mathrm{G} \times \mathrm{St}^{\mathrm{a}}$ & 10 & 0.1 & 0.4 & 0.9 & 9955 \\
\hline $\mathrm{Y} \times \mathrm{G} \times \mathrm{D}^{\mathrm{a}}$ & 8 & 0.4 & 4.0 & $<0.01$ & 9944 \\
\hline $\mathrm{Y} \times \mathrm{St} \times \mathrm{D}$ & 4 & 0.4 & 3.9 & 0.01 & 9958 \\
\hline $\mathrm{G} \times \mathrm{St} \times \mathrm{D}^{\mathrm{a}}$ & 2 & 1.4 & 0.7 & 0.7 & 9950 \\
\hline $\mathrm{Y} \times \operatorname{Si}(\mathrm{G} \times \mathrm{St})$ & 28 & 0.3 & 1.9 & $<0.01$ & 9899 \\
\hline $\mathrm{Si}(\mathrm{G} \times \mathrm{St}) \times \mathrm{D}$ & 6 & 2.0 & 22.2 & $<0.01$ & 9949 \\
\hline $\mathrm{Y} \times \mathrm{G} \times \mathrm{St} \times \mathrm{D}^{\mathrm{a}}$ & 8 & 0.3 & 2.8 & 0.02 & 9951 \\
\hline $\mathrm{Y} \times \mathrm{Si}(\mathrm{G} \times \mathrm{St}) \times \mathrm{D}$ & 24 & 0.1 & 0.6 & 0.9 & 9903 \\
\hline Residual & 528 & 0.2 & & & \\
\hline Total & 659 & & & & \\
\hline
\end{tabular}

0.05). For shallow habitats at the Easter group, mean relative abundance was higher in 2005 than in 2009 $(t=7.04, \mathrm{p}=0.02)$. For all other island groups, L. miniatus was more abundant in 2005 and 2006 than in 2009. In the shallows, L. miniatus was most abundant at the Wallabi group, much more so than populations in the shallows at the Pelsaert group $(2007,2008)$ or at the Easter group and North Island (2008).

A significant interaction of $\mathrm{Y} \times \mathrm{D}$ was observed (Table 2, Fig. 3). In 2006 Lethrinus miniatus were, on average, $2.5 \times$ more abundant in deep than shallow habitats

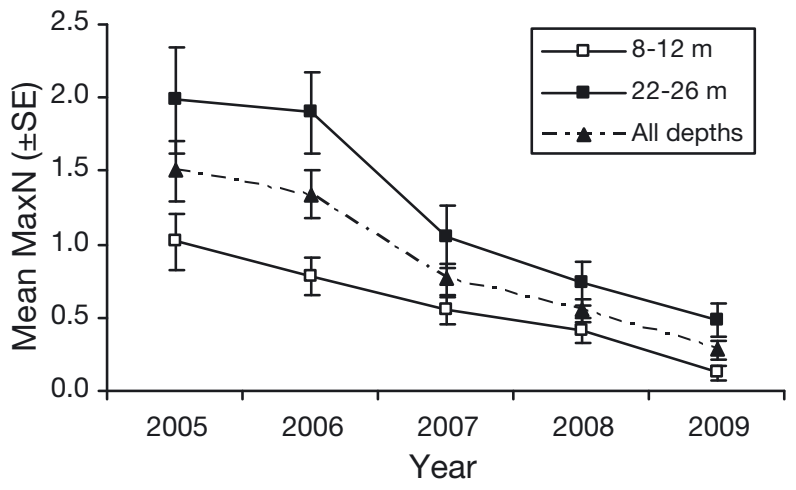

Fig. 3. Lethrinus miniatus. Overall mean $( \pm \mathrm{SE})$ relative abundance (MaxN) in shallow and deep habitats and overall (depths considered together) at the Houtman Abrolhos Islands between 2005 and 2009 (pairwise test $\mathrm{Y} \times \mathrm{D}, t=2.46, \mathrm{p}=0.04$ ). For these deep habitats, relative abundances were higher in 2005 and 2006 than in all other years, and in 2008 than in 2009 (all p < 0.05). In 2009, only $24 \%$ of the numbers of L. miniatus observed in 2005 were recorded in deep habitats (Fig. 3). For shallow surveys, numbers observed in 2009 were, on average, 70 to $87 \%$ lower than in all other years (all p < 0.01; Fig. 3). Relative abundances were also lower in 2007 and 2008 than they were in 2005 (46 and $59 \%$, respectively).

The relative abundance of Lethrinus miniatus declined significantly during the 5 yr study (Table 2; Fig. 3). Across both depths, from 2006 to 2007, there was a $43 \%$ decline in the relative abundance of individuals, from 2007 to 2008 a $28 \%$ decline and from 2008 to 2009 a $49 \%$ decline. In 2009 there were, on average, $5.4 \times$ fewer $L$. miniatus than in 2005 (Fig. 3; all depths pooled), i.e. a more than $80 \%$ decline in mean relative abundance in $5 \mathrm{yr}$.

\section{Length}

A total of 483 Lethrinus miniatus were measured from 2005 to 2009 ( $86 \%$ of those observed; Table 1). Lengths ranged from 161.1 to $552.1 \mathrm{~mm} \mathrm{FL,} \mathrm{with} \mathrm{the}$ majority of individuals between 320 and $390 \mathrm{~mm}$ FL (Table 1). Almost all individuals observed were larger than the minimum legal length for retention of $280 \mathrm{~mm}$ TL, i.e. ca. 255 mm FL (Table 1, Fig. 4). The total number of measured individuals both larger and smaller than the minimum legal size for retention of $280 \mathrm{~mm}$ TL declined over the $5 \mathrm{yr}$ of the study (Fig. 4).

A significant interaction of $\mathrm{G} \times \mathrm{St}$ was observed for Lethrinus miniatus mean length (Table 3). For the Easter group, L. miniatus were, on average, $34.9 \mathrm{~mm}$ $(10 \%)$ larger in length inside closed areas than in areas open to fishing (pairwise tests $\mathrm{G} \times \mathrm{St}$; $\mathrm{p}<0.01$ ). The mean length of $L$. miniatus did not differ significantly between open and closed areas at any of the other island groups (pairwise tests $\mathrm{G} \times \mathrm{St}_{;} \mathrm{p}>0.05$ ). Therefore, L. miniatus were larger, on average, in only 1 of the 4 closed areas. There was also no difference in the length of $L$. miniatus between locations open and closed to fishing across the years of the study $\left(\mathrm{Y} \times \mathrm{St}_{\text {; }}\right.$ Table 3 and all K-S tests; $\mathrm{p}>0.05$ ).

Considering the data for both open and closed areas together, the mean length of Lethrinus miniatus 


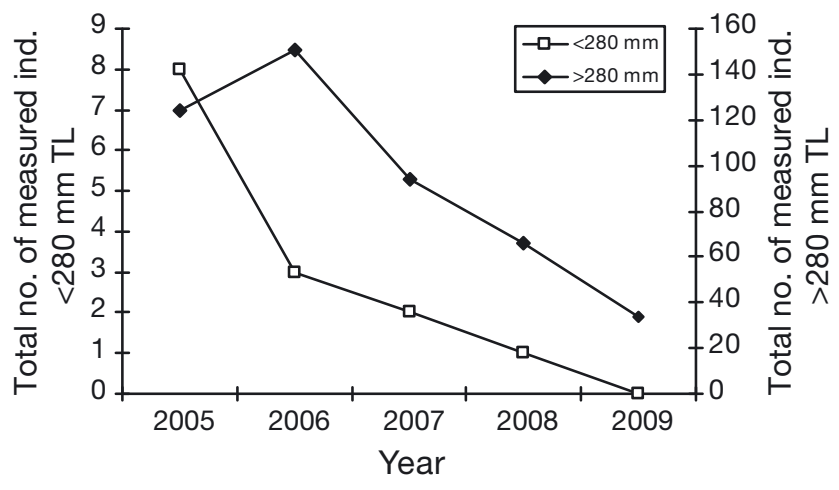

Fig. 4. Lethrinus miniatus. Total number of individuals measured in relation to the minimum legal size for retention of $280 \mathrm{~mm}$ total length (TL). Measured fork lengths (FL) were converted to $\mathrm{TL}$ using the equation $\mathrm{TL}=9.6+1.0575 \mathrm{FL}$ (see Leigh et al. 2006)

increased across the years from $327.9 \mathrm{~mm}$ in 2005 to $394 \mathrm{~mm}$ in 2009, and differed significantly among years (Table 3 ; Fig. 5). Pairwise $t$-tests showed that mean length increased significantly between 2005 and 2006 and between 2008 and 2009 (all pairwise tests for $Y_{i} \mathrm{p}<0.01$ ). The mean size of $L$. miniatus thus increased over the 5 yr study.

Length-frequency distributions in each year comprised a strong modal length class, which increased from 326 to $350 \mathrm{~mm}$ in 2005 to 351 to $375 \mathrm{~mm}$ in 2007

Table 3. Lethrinus miniatus. Results of PERMANOVA based on Euclidean distance dissimilarity of raw length data in response to the factors Year (Y), Island group (G), Status (St), Site (Si), Depth (D), and their interactions. Perm: permutation. Bold: significant at 0.05 level

\begin{tabular}{|c|c|c|c|c|c|}
\hline Source & df & MS & Pseudo- $F$ & $\mathrm{p}($ perm) & Perms \\
\hline Year (Y) & 4 & 12980 & 6.3 & $<0.01$ & 9952 \\
\hline Island group (G) & 3 & 2648.5 & 1.6 & 0.3 & 9973 \\
\hline Status (St) & 1 & 16212 & 7.8 & 0.2 & 9909 \\
\hline Depth (D) & 1 & 2891.2 & 1.2 & 0.3 & 9832 \\
\hline $\mathrm{Y} \times \mathrm{G}^{\mathrm{a}}$ & 9 & 1977.1 & 1.0 & 0.5 & 9937 \\
\hline $\mathrm{Y} \times \mathrm{St}$ & 4 & 2761.1 & 1.3 & 0.2 & 9946 \\
\hline $\mathrm{Y} \times \mathrm{D}$ & 4 & 2900 & 1.6 & 0.4 & 9971 \\
\hline $\mathrm{G} \times \mathrm{St}$ & 3 & 5230 & 2.8 & 0.02 & 9928 \\
\hline $\mathrm{G} \times \mathrm{D}^{\mathrm{a}}$ & 2 & 8087.3 & 2.7 & 0.1 & 9952 \\
\hline St $\times D$ & 1 & 21.2 & 0.01 & 0.9 & 9861 \\
\hline $\mathrm{Si}(\mathrm{G} \times \mathrm{St})$ & 8 & 1333.1 & 0.6 & 0.7 & 9941 \\
\hline $\mathrm{Y} \times \mathrm{G} \times \mathrm{St}^{\mathrm{a}}$ & 7 & 2634.3 & 1.3 & 0.2 & 9942 \\
\hline $\mathrm{Y} \times \mathrm{G} \times \mathrm{D}^{\mathrm{a}}$ & 7 & 3922.6 & 2.4 & 0.2 & 9963 \\
\hline $\mathrm{Y} \times \mathrm{St} \times \mathrm{D}$ & 4 & 730.7 & 0.5 & 0.7 & 9973 \\
\hline $\mathrm{G} \times \mathrm{St} \times \mathrm{D}^{\mathrm{a}}$ & 2 & 165.5 & 0.1 & 0.9 & 9968 \\
\hline $\mathrm{Y} \times \mathrm{Si}(\mathrm{G} \times \mathrm{St}) \times \mathrm{D}$ & 4 & 1107.4 & 0.5 & 0.7 & 9951 \\
\hline Residual & 418 & 2054.3 & & & \\
\hline Total & 482 & & & & \\
\hline
\end{tabular}

and 376 to $400 \mathrm{~mm}$ in 2009 (Fig. 5), albeit with shrinking sample sizes. K-S tests detected significant differences in length-frequency distributions between 2006 and 2007 and between 2006 and 2008 (p < 0.005, Bonferroni corrected for 8 tests). That is, the size structure of populations of Lethrinus miniatus changed from 2006 through to 2008.

\section{Behaviour}

Compared to other targeted fish species that were recorded at the Abrolhos Islands (i.e. baldchin groper Choerodon rubescens, West Australian dhufish Glaucosoma hebraicum, spangled emperor Lethrinus nebulosus, pink snapper Pagrus auratus, and coral trout Plectropomus leopardus), L. miniatus were consistently the first to feed from the bait basket at an average of 14.7 min into recording. Pagrus auratus were, on average, second to feed at $16.8 \mathrm{~min}$, followed by $L$. nebulosus (18 $\mathrm{min})$, C. rubescens (21.4 min), and Plectropomus leopardus (only observed to feed at on several occasions). L. miniatus fed from the bait basket on $78 \%$ of the deployments on which they were observed, which was much more frequently than all other aforementioned species (5 to $63 \%$ ).

\section{DISCUSSION}

The present study documents a decline in the relative abundance of Lethrinus miniatus at the Houtman Abrolhos Islands of more than $80 \%$ from 2005 to 2009 and negligible differences between areas open and closed to fishing. Furthermore, there has been a steady decline in the proportion of small individuals in the population over the $5 \mathrm{yr}$ of the study, such that in 2009 almost all individuals in the entire sampled population were larger than the minimum legal size for first capture (280 mm TL). This pattern of decline and a general lack of differentiation between MPAs and fished locations may be due to a number of factors, each of which are discussed here and include illegal fishing, overfishing, and low/variable recruitment.

The stereo BRUV sampling technique used in the present study provided a means of non-destructively assessing the relative abundance and size of Lethrinus miniatus of both legal 

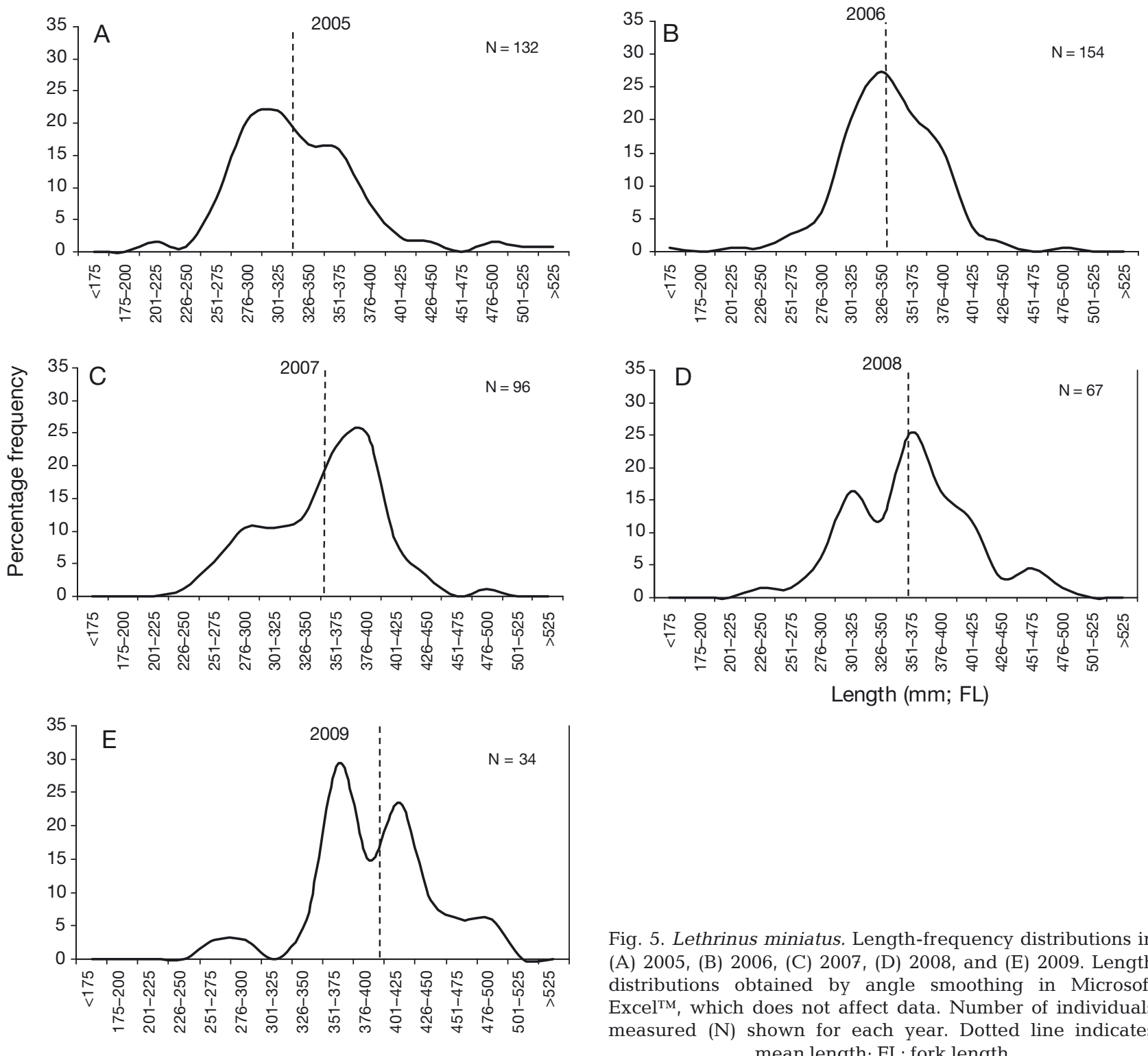

Length (mm; FL)

Fig. 5. Lethrinus miniatus. Length-frequency distributions in (A) 2005, (B) 2006, (C) 2007, (D) 2008, and (E) 2009. Length distributions obtained by angle smoothing in Microsoft Excel $^{\mathrm{TM}}$, which does not affect data. Number of individuals measured $(\mathrm{N})$ shown for each year. Dotted line indicates mean length; FL: fork length

and sub-legal lengths, i.e. above and below $280 \mathrm{~mm}$ TL (see Fig. 5). Stock assessment of the fishery for demersal species on the west coast of Australia has shown that catch per unit effort data from the commercial wetline, gillnet, and long-line fisheries and recreational boat-based survey data cannot, at present, be used to provide useful measures of relative abundance of the population. The absence of information on sublegal individuals means that knowledge of recruitment variability in the system is limited to data collected during specific monitoring programmes, which provide measures of relative recruitment strength once a cohort has recruited to the fishery. The ability to record and assess the relative abundance of sub-legal and juvenile L. miniatus (and other demersal species) using

the stereo BRUV technique would provide data on the annual variation in the relative strength of recruitment to the population, prior to their recruitment to the fishery. These data could potentially provide an ability to predict the future strength of recruitment to the fishery.

Lethrinus miniatus were consistently the first to feed directly from the bait basket, which suggests the species may be aggressive to fisher's bait. This is supported by observations that only after $L$. miniatus are caught do fishers begin to catch other prized species such as Glaucosoma hebraicum or Choerodon rubescens (D. McLean pers. obs.). High catchability of $L$. miniatus would exacerbate any effects of heavy fishing pressure or recruitment variability/failure, and predis- 
pose the species to a higher risk of overfishing than other heavily targeted fish species.

The large decline in relative abundance of Lethrinus miniatus evident from 2005 to 2009 may be exacerbated, as the year in which sampling began (2005) is likely to have been a year of high relative abundance due to the strong recruitment pulse visible in the length-frequency data. Thus, the $80 \%$ decline over the $5 \mathrm{yr}$ may be more extreme than if the population had been at normal levels at the commencement of sampling. However, regardless of natural variation in recruitment and stock levels, the decline to very low relative abundance is undoubtedly influenced not only by natural mortality and subsequent low recruitment years, but also by the effects of a history of high levels of exploitation. Declines in the relative abundance of $L$. miniatus over the 5 yr were not only observed in areas open to fishing but also in closed areas. While previously L. miniatus were significantly more abundant and larger inside closed areas than in areas open to fishing (2004 and 2005) (Watson et al. 2007, 2009), the present study found that this difference is generally no longer apparent (Fig. 2). Only at one of the 4 closed areas (Easter group) were individuals observed to be of larger size than in nearby areas open to fishing. Illegal fishing has been reported within closed area boundaries. However, the extent to which this activity occurs is considered to be low, although it is also difficult to be certain of a $100 \%$ detection rate given the remoteness and extent of the Abrolhos system. While L. miniatus can clearly benefit from protection from fishing (Watson et al. 2007, 2009), it is also possible that their vagile mobility (Williams et al. 2003) could mean that they cross protected area boundaries (Kaunda-Arara \& Rose 2004), especially given the small size of these closed areas at the Abrolhos. Abundances within closed areas could therefore decrease as a direct result of increasing fishing pressure in areas open to fishing.

Lethrinus miniatus is one of the top 5 species in terms of catch in the West Coast Demersal Scalefish Fishery, with total catches peaking at over $100 \mathrm{t}$ and with the majority of the catch being taken from an area that includes the Abrolhos Islands and waters immediately to the north. Since 2005, catches have declined, likely as a result of management restructuring within the demersal fishery and associated limits placed on effort (Department of Fisheries, Western Australia, unpubl. data, Fairclough et al. 2008). However, catch levels are historically much larger than those of another targeted species, Choerodon rubescens (Fairclough et al. 2009), whose stock status is used as an indicator of the health of the suite of demersal species in the Abrolhos Islands region. As C. rubescens has been experiencing overfishing in that region, the suite of other demersal species, particularly exploited spe- cies, is also considered to have a similar status at the Abrolhos Islands (Wise et al. 2007). With overfishing, one would first expect a decline in the abundance of large-bodied individuals, which has been observed here (Fig. 4). However, there has been a simultaneous decline in the relative number of small individuals (resulting in increasing mean lengths), which suggests that it is not simply overfishing that is responsible for declining numbers, but possibly also very low spawning and/or recruitment success.

Lethrinus miniatus, like many other tropical fish species, is at the southernmost limit of its range at the Houtman Abrolhos Islands. Previous studies have documented highly variable spawning activity in species living at the limit of their range (Fennessy \& Sadovy 2002, Williams et al. 2006). For example, $50 \%$ of female $L$. miniatus on reefs in the southern Great Barrier Reef do not spawn each season until reaching $\sim 450 \mathrm{~mm}$ FL and therefore exhibit periods of spawning omission (Williams et al. 2006). Spawning omission has also recently been documented for the coral trout, Plectropomus leopardus, at the Houtman Abrolhos, which is also at the southern limit of its range (J. How unpubl. data). Overfishing of a species that exhibits spawning omission, and therefore variable or inconsistent recruitment success, could have severe consequences for its local abundance and potential lead-on effects on trophic structure. Length-frequency histograms (Fig. 5) show an ageing population with little or no evidence of recruitment into the population over the past $5 \mathrm{yr}$, which suggests inconsistent recruitment is occurring at the Abrolhos Islands. Further monitoring should be a priority to see if this continues. If $L$. miniatus is exhibiting spawning omission or not spawning until reaching a larger size like some east coast populations, then the legal size limit applied at the Abrolhos may not be allowing females to spawn before being fished.

More than $95 \%$ of Lethrinus miniatus measured from stereo-video footage during the present study were larger than their minimum legal length for retention of $280 \mathrm{~mm}$ TL (approx. $255 \mathrm{~mm}$ FL). Despite $L$. miniatus being one of the largest lethrinid species, reaching a maximum reported length of $900 \mathrm{~mm}$ (Allen 2004), its length at sexual maturity, on which a minimum legal length (MLL) is based, is not known in Western Australia. Thus, along with other lethrinids in Western Australia, where little is known of their biology, it has been assigned a generic MLL of $280 \mathrm{~mm}$ TL. In Western Australia, other large lethrinid species, i.e. L. laticaudis and L. nebulosus, have MLLs of $320 \mathrm{~mm}$ TL and $410 \mathrm{~mm}$ TL, respectively, based on knowledge of their reproductive biology. Our data suggest that the current MLL for L. miniatus in Western Australia needs to be reviewed. The minimum legal size for $L$. miniatus 
on the east coast of Australia is $100 \mathrm{~mm}$ larger, at $380 \mathrm{~mm}$ TL (350 mm FL). According to a survey by Williams et al. (2006), the east coast MLL allows all females to reach sexual maturity, i.e. $95 \%$ of individuals were expected to be mature at $333 \mathrm{~mm}$ FL (estimated logistic maturation schedule). Assuming a similar logistic function for Houtman Abrolhos populations, then a MLL of $280 \mathrm{~mm}$ TL would mean $39 \%$ (2005) to $90 \%$ (2009) of fish measured would be expected to be mature.

Growth patterns and some reproductive parameters of east coast populations of Lethrinus miniatus have been shown to vary spatially (Williams et al. 2003, 2006, 2007); thus the reproductive biology of west coast stocks of $L$. miniatus may also differ, and needs to be documented. New management measures implemented in 2009 aim to achieve a $50 \%$ reduction in the catch of demersal species on the west coast of Australia, which includes the Abrolhos Islands (Wise et al. 2007). Thus, ongoing monitoring of the relative abundance and size structure of $L$. miniatus would assist in demonstrating whether such a broad management measure is appropriate for this species. However, information on the biology of L. miniatus at the Abrolhos Islands, including reproductive characteristics, growth and age structure, mortality rates, and its stock structure is more urgently required. Following such research, a review of current management measures, such as the MLL, and a more comprehensive assessment of fishing mortality can be undertaken.

Acknowledgements. This study was conducted with logistical assistance from the Department of Fisheries, Government of Western Australia (DoF) and The University of Western Australia (UWA). Financial assistance was received from UWA and from the West Australian and Australian Governments Natural Heritage Trust initiative (NHT) through the Northern Agricultural Catchment Council (NACC). We also thank SONY Australia and R. Scott in the UWA workshop for construction of the stereo-video systems. Comments on the manuscript from anonymous reviewers were gratefully received.

\section{LITERATURE CITED}

Allen G (2004) Marine fishes of tropical Australia and SouthEast Asia. A field guide for anglers and divers. Western Australian Museum, Perth

Anderson MJ (2001) A new method for non-parametric multivariate analysis of variance. Austral Ecol 26:32-46

Bean K, Mapstone BD, Davies CR, Murchie CD, Williams AJ (2003) Gonad development and evidence of protogyny in the red-throat emperor on the Great Barrier Reef. J Fish Biol 62:299-310

Begg GA, Mapstone BD, Williams AJ, Adams A, Davies CR, Lou DC (2005) Multivariate life-history indices of exploited coral reef fish populations used to measure the performance of no-take zones in a marine protected area. Can J Fish Aquat Sci 62:679-692

Cappo M, Speare P, Wassenberg TJ, Harvey E, Rees M, Hey- ward A, Pitcher R (2001) Use of baited remote underwater video stations (BRUVS) to survey demersal fish-how deep and meaningful? In: Harvey ES, Cappo M (eds) Direct sensing of the size frequency and abundance of target and non-target fauna in Australian Fisheries. 4-7 September 2000, Rottnest Island, Western Australia. Fisheries Research and Development Corporation, Perth, p 63-71

Cappo M, Speare P, De'ath G (2004) Comparison of baited remote underwater video stations (BRUVS) and prawn trawls for assessments of fish biodiversity in inter reefal areas of the Great Barrier Reef Marine Park. J Exp Mar Biol Ecol 302:123-152

Carpenter KE, Allen GR (1989) FAO species catalogue, Vol 9. Emperor fishes and large-eye breams of the world (family Lethrinidae). FAO Fish Synop 125(9):1-118

> Ebisawa A, Ozawa T (2009) Life-history traits of eight Lethrinus species from two local populations in waters off the Ryuku Islands. Fish Sci 75:553-566

Fairclough D, Keay I, Johnson C, Lai E (2008) West coast demersal scalefish fishery status report. In: Fletcher WJ, Santoro K (eds) State of the fisheries report 2007/08. Department of Fisheries, Government of Western Australia, Perth, p 68-76

Fairclough D, Johnson C, Lai E (2009) West coast demersal scalefish fishery status report. In: Fletcher WJ, Santoro K (eds) State of the fisheries report 2008/09. Department of Fisheries, Government of Western Australia, Perth, p 71-79

Fennessy ST, Sadovy Y (2002) Reproductive biology of a diandric protogynous hermaphrodite, the serranid Epinephelus andersoni. Mar Freshw Res 53:147-158

> Halpern BS (2003) The impact of marine reserves: Have reserves worked and does reserve size matter? Ecol Appl 13:117-137

Harborne AR, Mumby PJ, Kappel CV, Dahlgren CP and others (2008) Reserve effects and natural variation in coral reef communities. J Appl Ecol 45:1010-1018

Harvey ES, Shortis MR (1996) A system for stereo-video measurement of subtidal organisms. Mar Technol Soc J 29: $10-22$

Harvey ES, Shortis MR (1998) Calibration stability of an underwater stereo-video system: implications for measurement accuracy and precision. Mar Technol Soc J 32: 3-17

Harvey E, Fletcher D, Shortis M (2001) Improving the statistical power of length estimates of reef fish: a comparison of estimates determined visually by divers with estimates produced by a stereo-video system. Fish Bull 99:72-80

> Harvey E, Fletcher D, Shortis M (2002) Estimation of reef fish length by divers and by stereo-video: a first comparison of the accuracy and precision in the field on living fish under operational conditions. Fish Res 57:255-265

> Harvey E, Fletcher D, Shortis MR, Kendrick GA (2004) A comparison of underwater visual distance estimates made by SCUBA divers and a stereo-video system: implications for underwater visual census of reef fish abundance. Mar Freshw Res 55:573-580

> Kaunda-Arara B, Rose GA (2004) Out-migration of tagged fishes from marine reef national parks to fisheries in coastal Kenya. Environ Biol Fishes 70:363-371

Kelleher G (1999) Guidelines for Marine Protected Areas. IUCN, Gland and Cambridge

Leigh GM, Williams AJ, Begg GA, Gribble NA, Whybird OJ (2006) Stock assessment of the Queensland east coast red throat emperor (Lethrinus miniatus) fishery. Sustainable Fisheries Unit, Animal Science, Queensland Government Department of Primary Industries and Fisheries. Available at www.dpi.qld.gov.au/28_11074.htm 
Mapstone BD, Davies CR, Little LR, Punt AE and others (2004) The effects of line fishing on the Great Barrier Reef and evaluations of alternative potential management strategies. CRC Reef Research Centre Technical Report No 52. CRC Reef Research Centre, Townsville

Marriott RJ, Jarvis N, Adams DJ, Gallash AE, Norriss J, Newman SJ (2010) Maturation and sexual ontogeny in the spangled emperor, Lethrinus nebulosus (Forsskal, 1775), on the northern Ningaloo Reef, Western Australia. J Fish Biol 76(6):1396-1414

Molloy PP, Goodwin NB, Côté IM, Reynolds JD, Gage MJG (2007) Sperm competition and sex change: a comparative analysis across fishes. Evolution 61:640-652

Molloy PP, Reynolds JD, Gage MJG, Mosqueriac L, Cote IM (2008) Links between sex change and fish densities in marine protected areas. Biol Conserv 141:187-197

Nardi K, Jones GP, Moran MJ, Cheng YW (2004) Contrasting effects of marine protected areas on the density of two exploited reef fishes at the sub-tropical Houtman Abrolhos Islands, Western Australia. Environ Conserv 31: 160-168

Penn JW, Fletcher WJ (2010) The efficacy of sanctuary areas for the management of fish stocks and biodiversity in WA waters. Fisheries Research Report No. 169. Department of Fisheries, Western Australia, Perth

Platten JR, Tibbets IR, Sheaves MJ (2002) The influence of increased line-fishing mortality on the sex ratio and age of sex reversal of the venus tusk fish. J Fish Biol 60: 301-318

Priede IG, Bagley PM, Smith A, Creasey S, Merrett NR (1994) Scavenging deep demersal fishes of the Porcupine Seabight, north-east Atlantic: observations by baited camera, trap and trawl. J Mar Biol Assoc UK 74:481-498

SeaGIS (2008) PhotoMeasure and EventMeasure. SeaGIS. www.seagis.com.au

van Herwerden L, Aspden WJ, Newman SJ, Pegg GG, Briskey L, Sinclair W (2009) A comparison of the population genetics of Lethrinus miniatus and Lutjanus sebae from the east and west coasts of Australia: evidence for panmixia and isolation. Fish Res 100 (2): 148-155

> Watson DL, Harvey ES, Anderson MJ, Kendrick GA (2005) A comparison of temperate reef fish assemblages recorded

Editorial responsibility: Tim McClanahan,

Mombasa, Kenya by three underwater stereo-video techniques. Mar Biol 148:415-425

Watson DL, Harvey ES, Kendrick GA, Nardi K, Anderson MJ (2007) Protection from fishing alters the species composition of fish assemblages in a temperate-tropical transition zone. Mar Biol 152:1197-1206

> Watson DL, Anderson MJ, Kendrick GA, Nardi K, Harvey ES (2009) Effects of protection from fishing on the lengths of targeted and non-targeted fish species at the Houtman Abrolhos Islands, Western Australia. Mar Ecol Prog Ser 384:241-249

Welch DJ, Mapstone BD, Begg GA (2008) Spatial and temporal variation and effects of changes in management in discard rates from the commercial reef line fishery of the Great Barrier Reef, Australia. Fish Res 90:247-260

Williams AJ, Davies CR, Mapstone BD, Russ GR (2003) Scales of spatial variation in demography of a large coral reef fish: an exception to the typical model? Fish Bull 101: $673-683$

> Williams AJ, Davies CR, Mapstone BD (2006) Regional patterns in reproductive biology of Lethrinus miniatus on the Great Barrier Reef. Mar Freshw Res 57:403-414

Williams AJ, Mapstone BD, Davies CR (2007) Spatial patterns in cohort-specific mortality of red throat emperor, Lethrinus miniatus, on the Great Barrier Reef. Fish Res 84:328-337

Willis TJ, Millar RB, Babcock RC (2000) Detection of spatial variability in relative density of fishes: comparison of visual census, angling, and baited underwater video. Mar Ecol Prog Ser 198:249-260

Wise BS, St John J, Lenanton RC (2007) Spatial scales of exploitation among populations of demersal scalefish: implications for management. I. Stock status of the key indicator species for the demersal scalefish fishery in the West Coast Bioregion. Final report to the Fisheries Research and Development Corporation on Project No. 2003/052. Fisheries Research Report No. 163, Department of Fisheries, Western Australia, Perth. http://www.fish.wa. gov.au/docs/frr/frr163/frr163.pdf

Woodley S, Loneragan N, Babcock R (2010) Report on the scientific basis for and the role of marine sanctuaries in marine planning. Report by the Marine Scientific Panel for the Government of Western Australia, Perth

Submitted: November 30, 2009; Accepted: September 16, 2010 Proofs received from author(s): November 11, 2010 